\begin{tabular}{|c|l|}
\hline Title & Flood disturbance and predator-prey effects on regional gradients in species diversity \\
\hline Author(s) & Mori, Terutaka; Saitoh, Takashi \\
\hline Citation & $\begin{array}{l}\text { Ecology, 95(1), 132-141 } \\
\text { https:/doi.org/10.1890/13-0914.1 }\end{array}$ \\
\hline Issue Date & 201401 \\
\hline Doc URL & http://hdl.handle.net/2115/54921 \\
\hline Rights & Copyright by the Ecological Society of A merica \\
\hline Type & article \\
\hline File Information & 13 -0914\%2E1.pdf \\
\hline
\end{tabular}

Instructions for use 


\title{
Flood disturbance and predator-prey effects on regional gradients in species diversity
}

\author{
Terutaka Mori ${ }^{1,3}$ And TAKashi Saitoh ${ }^{1,2}$ \\ ${ }^{1}$ Graduate School of Environmental Science, Hokkaido University, North 10, West 5, Sapporo 0600811 Japan \\ ${ }^{2}$ Field Science Center, Hokkaido University, North 11, West 10, Sapporo 0600811 Japan
}

\begin{abstract}
The effects of both abiotic factors and biotic interactions among guilds (i.e., inter-guild effects) have been suggested to be important for understanding spatial variation in species diversity; however, compared to the abiotic effects, the processes by which the interguild effects are mediated have been little described. Hence, we investigated stream invertebrate assemblages on Hokkaido Island, Japan, and assessed how the processes of determining regional patterns in species diversity differed among guilds (collector-filterers, collectorgatherers/shredders, scrapers, and predators) by taking both inter-guild and abiotic effects into consideration using Bayesian networks. Collector-gatherers/shredders, collector-filterers, and predators exhibited significant regional gradients in taxonomic richness. Gradients in the former two guilds can be generated by variation in flood disturbance regardless of interactions with other guilds. The gradient in predator taxonomic richness was indirectly related to the disturbance and was directly generated by bottom-up effects through their prey (collectorgatherers/shredders and collector-filterers). We found that not only environmental factors, but also inter-guild effects may be essential for forming the regional gradient in predators, unlike those for collector-gatherers/shredders and collector-filterers. The processes underlying the regional variation in taxonomic richness of the three guilds are interpreted in terms of the "more individuals" hypothesis, facilitation, and predator-prey relationships.
\end{abstract}

Key words: Bayesian networks; community density; disturbance; facilitation; functional feeding guilds; Hokkaido Island, Japan; latitudinal gradients; predator-prey relationships; species richness; stream invertebrates.

\section{INTRODUCTION}

Spatial patterns in species diversity have long fascinated ecologists (Rosenzweig 1995). In particular, the latitudinal gradient in species diversity, which decreases from tropical regions to the poles, is one of the most striking patterns in ecology (Willig et al. 2003, Hillebrand 2004), and has been well documented for a variety of taxa in both terrestrial and aquatic ecosystems (e.g., Pearson and Boyero 2009). Many hypotheses have been proposed to explain these latitudinal gradients (e.g., Rohde 1992, Rosenzweig 1995), and both empirical and theoretical studies have been performed in an effort to validate these hypotheses (Hubbell 2001, Allen et al. 2002, Hawkins et al. 2003). However, a gap remains between empirical and theoretical studies in terms of identifying the actual determinant of the gradients (Scheiner and Willig 2005). Specifically, nearly all of the theoretical models focus on the gradient in a single guild or trophic level (e.g., Hubbell 2001), whereas most empirical studies have examined the gradients in assemblages belonging to a particular taxonomic level,

Manuscript received 15 May 2013; accepted 11 June 2013. Corresponding Editor: L. Stone.

${ }^{3}$ Present address: Aqua Restoration Research Center, Public Works Research Institute, Kawashima Kasada-machi, Kakamigahara 5016021 Japan. E-mail: mori55@pwri.go.jp which may include several guilds and trophic levels (Lyons and Willig 1999, Hawkins et al. 2003, Pearson and Boyero 2009).

Given that latitude is a proxy for environmental gradients, the external factors associated with latitude, such as solar radiation and climate, would be expected to be determinants of the gradient in species diversity (Allen et al. 2002, Hawkins et al. 2003, Fuhrman et al. 2008). However, the generality of the identified determinants has been a subject of controversy (Hawkins et al. 2003, Willig et al. 2003). Although an environmental factor may have comparable effects on organisms with similar traits (i.e., guild members), its effects may differ among guilds. A significant factor for one guild may have no effect on other guilds. When the effects of an environmental factor are analyzed in assemblages with several guilds, these effects may be diluted because guilds that are unaffected or little affected by that factor could be included in the analysis. Thus, environmental determinants should be identified for species diversity per guild (Boyero et al. 2011). In addition, if the species diversity in a guild is strongly dependent on that in another guild, spurious relationships between the species diversity in the dependent guild and an environmental factor that influences the other guild could emerge. For example, if the species diversity of prey assemblages exhibits a latitudinal gradient and has positive effects on 
that of predator assemblages (Jeffries and Lawton 1985, Warren and Gaston 1992), predator diversity would also show a latitudinal gradient through bottom-up effects. Since such a gradient in predator diversity cannot be elicited without the effects of prey assemblages, it would not make sense to analyze the relationship between the dependent guild and an external factor that changes with the gradient. It is therefore important to consider the inter-guild relationships in an assemblage and to focus on an appropriate combination of a guild and an influential factor (Buckley et al. 2003, Boyero et al. 2011).

The effects of inter-guild relationships (i.e., inter-guild effects) have been suggested to be important for understanding latitudinal gradients in species diversity (Buckley et al. 2003, Hillebrand 2004, Mori et al. 2010). However, we have not succeeded in detecting the processes at large spatial scales, although biological processes such as inter-guild effects determining species diversity have been identified at small spatial scales (e.g., Hixon and Beets 1993). Compared to small spatial scales, large spatial scales, such as globe and continent, usually incorporate greater abiotic and biotic heterogeneity (Underwood et al. 2005), and thus, inter-guild effects may be obscured by the heterogeneity at large spatial scales (Huston 1999). Interactions among guilds may, for example, vary between temperate and tropical systems due to different regional species pools (Freestone et al. 2011). Thus, spatial scales should be appropriately determined to identify the processes by which inter-guild effects generate spatial variation in diversity, and downscaling from latitudinal gradients at global and continental scales to those at regional scales (i.e., regional gradients) is a rational approach for demonstrating inter-guild effects on the gradients.

Stream invertebrate assemblages in Hokkaido Island, Japan, provide a good system for studying the association between inter-guild effects and spatial patterns in species diversity. The communities have been assembled from a common species pool (Mori et al. 2010). In addition, the types of food ingested are relatively well defined (Poff et al. 2006); they can be categorized into five functional feeding guilds (collector-filterer, collector-gatherer, scraper, predator, and shredder; Merritt and Cummins 1996, Poff et al. 2006). Previous studies have suggested that prey assemblages have effects on predator assemblages and vice versa (Jeffries and Lawton 1985, Warren and Gaston 1992, Wallace et al. 1999, Dudgeon et al. 2010). For example, since prey species types are considered as the niche dimensions for predator species, higher prey species richness may provide a higher niche quality for predators (Jeffries and Lawton 1985). Similarly, habitat modification by net-spinning collector-filterers may facilitate and/or inhibit colonization by other guilds (Englund 1993, Englund and Evander 1999). Thus, a spatial pattern in species diversity of a guild may be modified by inter- guild effects such as predator-prey relationships, facilitation, and inhibition.

In the present study, we examined regional gradients in the taxonomic richness of stream invertebrate assemblages on Hokkaido Island for each of four different guilds (collector-filterer, collector-gatherer/ shredder, scraper, and predator). In a previous study, we showed that the taxonomic richness of the entire stream invertebrate assemblage increases with latitude (Mori et al. 2010). This pattern originated mainly from a directional variation in flood disturbance through their community density (i.e., number of individuals). On the basis of these findings, we asked if regional gradients differ among the guilds, which are the environmental factors that are linked to the gradients, and how is the gradient in one guild influenced by other guilds. Through answering these questions, we provide convincing evidence of differences in the processes underlying the regional gradients among guilds; the gradients in taxonomic richness of both collector-gatherers/ shredders and collector-filterers originated from flood disturbance, whereas the gradient in that of predators was caused by not only the disturbance but also bottomup effects through their prey.

\section{Materials And Methods}

\section{Study sites}

The study was conducted in June 2004 in 30 mountain streams on Hokkaido Island (Appendix A), the northernmost island of Japan $\left(41^{\circ} 24^{\prime} \mathrm{N}\right.$ to $45^{\circ} 31^{\prime} \mathrm{N}, 139^{\circ} 46^{\prime} \mathrm{E}$ to $145^{\circ} 49^{\prime} \mathrm{E}$; Fig. 1), which encompasses an area of about $79500 \mathrm{~km}^{2}$. Mountain ridges run north to south in the middle of the island and high mountains are located in the southwestern part (Fig. 1).

\section{Field procedures}

In each stream, a 20-m riffle was selected as a study reach. Each study reach was evenly divided into three sections, and benthic invertebrates and periphyton were sampled from each section (Appendix B). Within each study reach, five evenly spaced transects with three evenly spaced measuring points were established. Water velocity, depth, and substratum type were measured at each point after sampling stream invertebrates (Appendix B). Water samples for chemical analysis were collected directly from each study reach using polyethylene bottles.

\section{Laboratory procedures and data treatment}

In the laboratory, invertebrates were identified to the lowest possible taxonomic level, usually genus or species, and individual dry mass was estimated (Appendix B). Subsequently, invertebrates were assigned to one of five functional feeding groups (collector-filterer, collector-gatherer, shredder, scraper, and predator) based on Merritt and Cummins (1996) and Kawai and Tanida (2005). Collector-gatherers and shredders mainly feed on deposited benthic fine and coarse particulate 
a) Accumulated precipitation

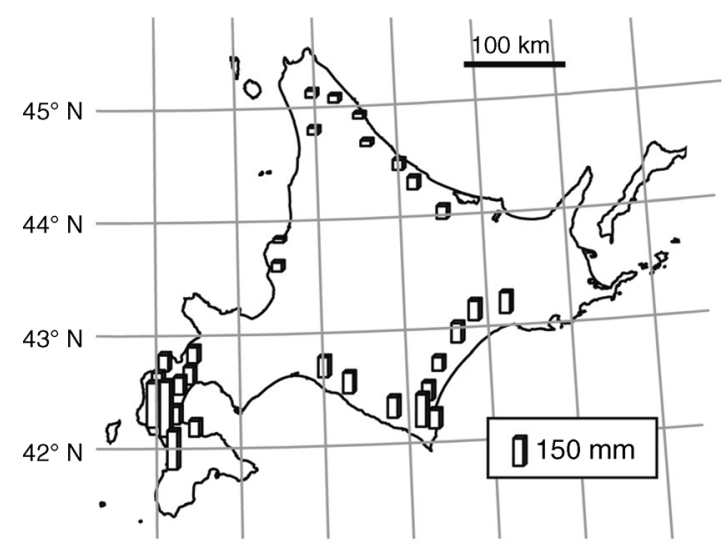

$140^{\circ} \mathrm{E}$ $142^{\circ} \mathrm{E}$ b) Elevation

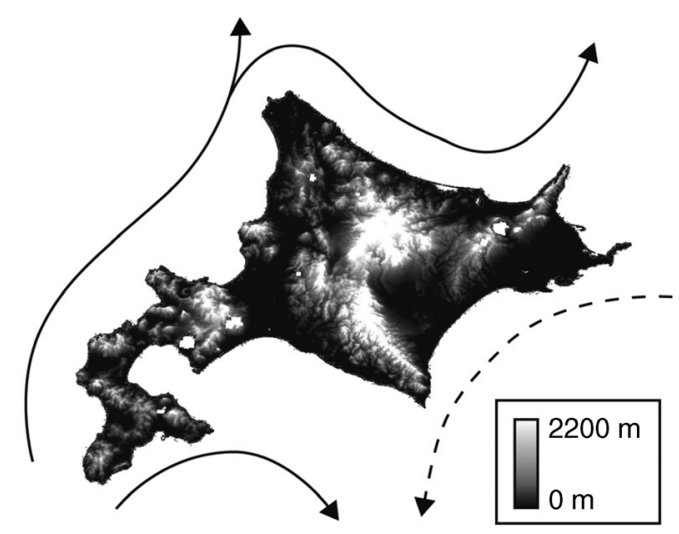

d) Temperature

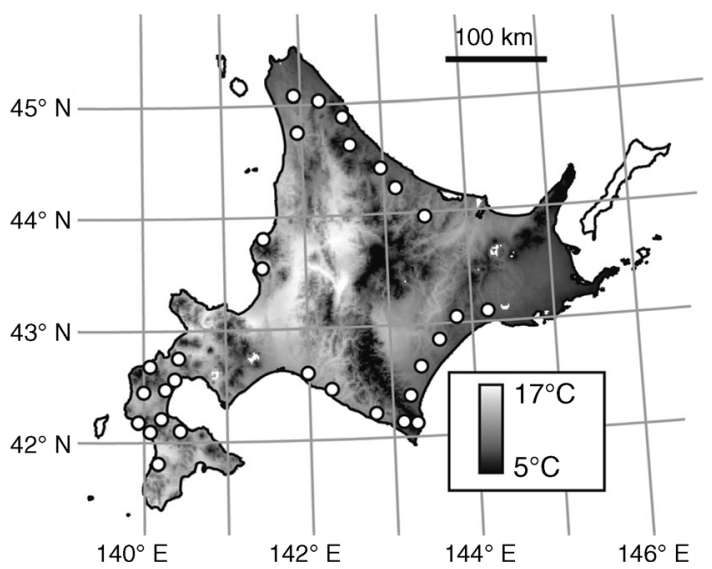

FIG. 1. (a) Accumulated precipitation during the month before sampling in 2004, (b) topography (elevation above sea level), and 30-year means for the period 1971-2000 of mean June (c) precipitation and (d) temperature in Hokkaido Island, Japan. Solid and dotted arrows represent warm and cool currents, respectively. Open circles and boxes indicate the locations of the 30 study streams.

organic matter, respectively; collector-filterers mainly consume suspended particulate organic matter (i.e., seston); and scrapers and predators mainly feed on periphyton on stream substrates and on other benthic invertebrates, respectively (Merritt and Cummins 1996, Kawai and Tanida 2005). Since there was a low ratio of shredders to total invertebrates in the study area (ratio of abundance $=0.03$ ), and since collector-gatherers and shredders feed on differently sized but similar food resources, we considered these two guilds as a single guide (collector-gatherers/shredders). Accordingly, in this study, stream invertebrates were categorized into four guilds based on the types of food ingested. Three samples in each study reach were pooled, and the observed number of taxa and individuals per study reach were used as indicators of taxonomic richness and community density, respectively. Total biomass was calculated by summing the dry masses of all individuals observed in each study reach. Logarithmic transformations were performed for community density data in order to standardize variances.

The Froude number, substrate heterogeneity, total dissolved nitrogen, total dissolved phosphorus, concentration of seston, chlorophyll (chl.) a estimates, and deposited benthic particulate organic matter (BPOM) were calculated in each study reach (Appendix B). Mean temperature during the month before sampling was calculated from the Japan Meteorological Agency data obtained from the meteorological stations nearest each study site. Accumulated precipitation during the period was also quantified from the data in each study reach, since Mori et al. (2010) indicate that the accumulated precipitation can be used as a proxy for flood disturbance in this study system. Thirty-year means for the extrapolated average temperature and precipitation in June for the period 1971 to 2000 were mapped from 
the Mesh Climatic Data of Japan (Japan Meteorological Agency 2002), which were given for each $1 \times 1 \mathrm{~km}$ mesh. Catchment area, catchment slope, and altitude were derived from digital elevation maps using geographical information system software. Logarithmic transformations were performed for the disturbance (i.e., accumulated precipitation) in order to standardize variances.

\section{Statistical analyses}

The relationship between community density and total biomass was examined using linear regression analyses. We also assessed the regional latitudinal gradients in 12 environmental variables (i.e., temperature, precipitation, catchment area, catchment slope, altitude, Froude number, substratum heterogeneity, total dissolved nitrogen, total dissolved phosphorus, seston, BPOM, and chl. a) and taxonomic richness of the four guilds using linear regression analyses. The statistical significance of the regression analyses was evaluated using a likelihood ratio test. We considered the results to be statistically significant when $P<0.05$. These analyses were performed using the $\mathrm{R}$ environment for statistical computing (R Development Core Team 2009).

To identify which guilds were directly influenced by environmental factors and to examine how inter-guild effects influenced the regional gradients of the guilds, we used Bayesian networks (McMahon 2005), which are one of the machine learning techniques, combining graphical models with multivariate Bayesian statistics. Since Bayesian networks can infer dependence relationships between variables (Hawkins et al. 2010, van Steensel et al. 2010), they have been used to identify which variables (i.e., nodes) in a network depend on which of the other variables and which variables are conditionally independent (McMahon 2005, Needham et al. 2006). If two variables are independent given the state of a third variable, then they are said to be conditionally independent. Given evidence about the state of a variable or set of variables, the state of other variables can be inferred (Needham et al. 2006). Thus, Bayesian networks can identify causal relationships among diverse types of data, and thereby suggest hypotheses that can be tested experimentally (Hawkins et al. 2010).

Bayesian networks are graphical representations of a joint probability distribution of a set of variables of interest, and the joint probability distribution of the variables is as follows:

$$
P(x)=\prod_{v \in V} P\left(x_{\mathrm{v}} \mid x_{\mathrm{pa}(\mathrm{v})}\right)
$$

where $v$ denotes a node in $V$, which is the set of nodes, and $\mathrm{pa}(v)$ denotes the parents of that node. For continuous nodes, the conditional distributions are given by Gaussian linear models as

$$
x_{\mathrm{v} \mid \mathrm{pa}(\mathrm{v})} \sim \mathcal{N}\left(\boldsymbol{\alpha}_{\mathrm{v} \mid \mathrm{pa}(\mathrm{v})}+\boldsymbol{\beta}_{\mathrm{v} \mid p a(\mathrm{v})} \mathbf{x}_{\mathrm{pa}(\mathrm{v})}, \sigma_{\mathrm{v} \mid \mathrm{pa}(\mathrm{v})}^{2}\right)
$$

where $\alpha_{v \mid \operatorname{pa}(v)}$ is a regression intercept, $\boldsymbol{\beta}_{v \mid p a(v)}$ is a vector of partial regression coefficients, and $\sigma^{2} v \mid$ pa(v) is the conditional variance (Bøttcher and Dethlefsen 2003).

Bayesian networks form a directed acyclic graph (DAG), in which no directed path leads from a given node to itself. Variables are represented as nodes in a network and are connected by arrows, which indicate conditional dependence. A link between two nodes, represented by an arrow from node $A$ (parent) to node $B$ (child), indicates that $A$ is a causal variable of $B$. We conveniently represented a putative network using rounded squares, lines, and arrows (Fig. 2). Rounded squares indicate variables (i.e., nodes), lines indicate that both of two connected variables have a potential to be causal, and arrows indicate that a link from one variable to another variable is allowed but not the reverse. Unconnected variables are considered to be unrelated to each other.

In this study, we assessed the relationships among latitude, five environmental factors (i.e., disturbance, total dissolved nitrogen, seston, BPOM, and chl. $a$ ), and the taxonomic richness and community density of the four studied guilds using Bayesian networks (Appendix C). Although several techniques can be used to learn a Bayesian network from particular data and to detect the network that gives the best representation of the data (Bøttcher and Dethlefsen 2003, Scutari 2010), we used a greedy search based on the Bayes factor and an uninformative prior distribution for the joint probability (Appendix C). Subsequently, standardized partial regression coefficients (SPRC) were calculated to assess the relative importance of each explanatory variable in the best representing network by multiplying the partial regression coefficient by the standard deviation of its explanatory variable and dividing it by the standard deviation of the response variable (Sokal and Rohlf 1995). Bayesian networks were constructed using the $R$ environment for statistical computing ( $\mathrm{R}$ Development Core Team 2009) with the associated package deal (Bøttcher and Dethlefsen 2003).

\section{RESULTS}

A total of 94 taxa and 30983 individuals were found in the samples collected from the 90 sections of the 30 sites. The numbers of taxa and individuals per Surber sample ranged from 14 to 37 and from 45 to 1078 , respectively. When each taxon was assigned to one of the four studied guilds, the greatest taxonomic richness was found for collector-gatherers/shredders (37\%), followed by predators (34\%), scrapers (21\%), and collector-filterers (9\%). Similarly, community density was numerically dominated by collector-gatherers/ shredders $(44 \%)$, followed by scrapers $(31 \%)$, predators (20\%), and collector-filterers (5\%). Total biomass significantly increased with community density in collector-gatherers/shredders, scrapers, and predators $(P=0.001-0.003)$, but not in collector-filterers $(P=$ $0.13)$. 


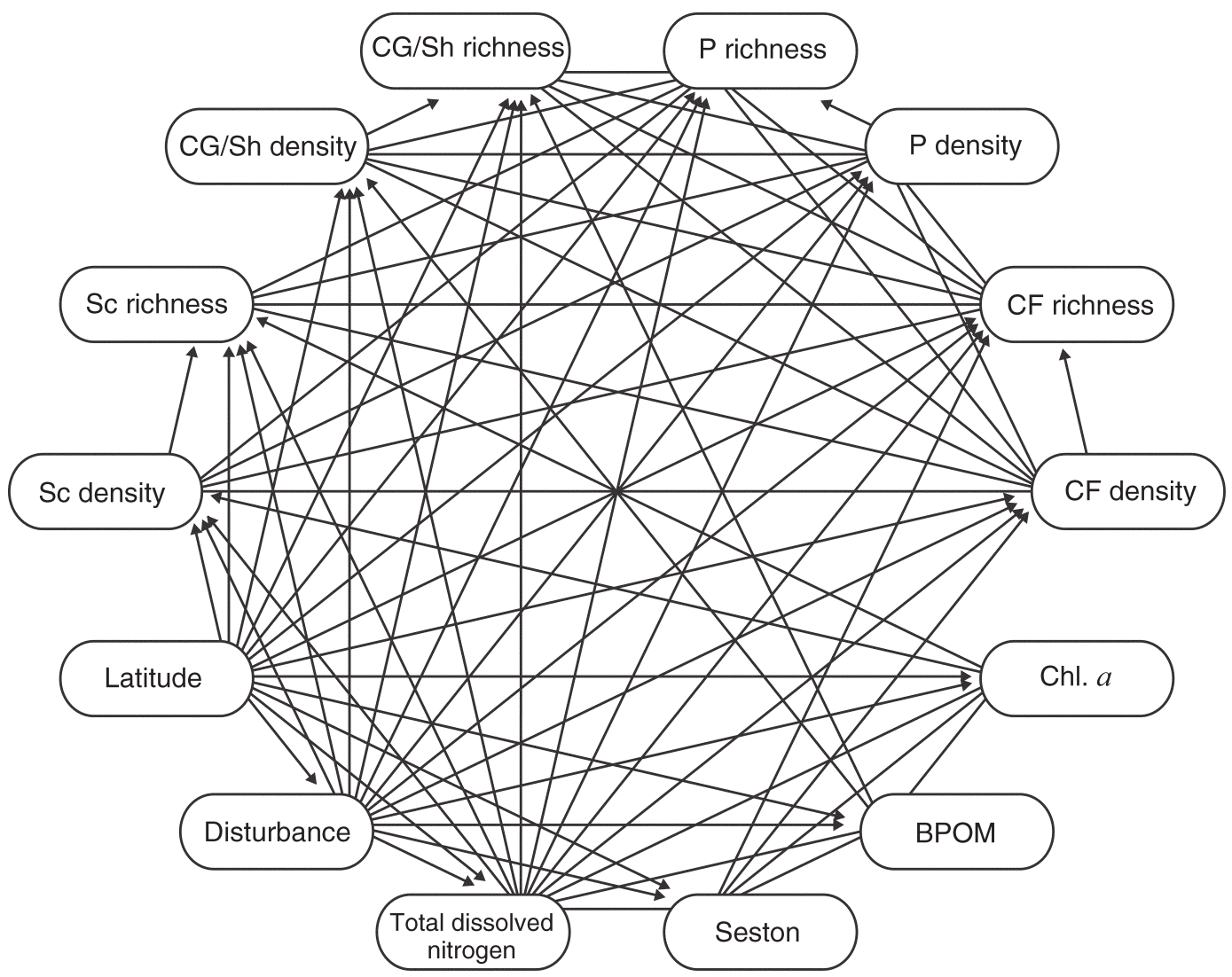

FIG. 2. Putative network. Rounded rectangles represent variables (i.e., nodes). Arrows indicate that a link from one variable (i.e., node) to another variable is allowed, but not the reverse. Lines indicate that both variables can be causal. Abbreviations are: $\mathrm{CF}$, collector-filterers; CG, collector-gatherers; Sc, scrapers; Sh, shredders; P, predators; BPOM, benthic particulate organic matter; Chl. $a$, chlorophyll $a$.

\section{Regional gradients in environmental variables and stream invertebrates}

Significant regional latitudinal gradients were observed in precipitation and catchment slope (Fig. 3, Table 1), which decreased from south to north. The degree of the gradients was stronger for precipitation than for catchment slope (Table 1). Temperature, catchment area, altitude, Froude number, substrate heterogeneity, total dissolved nitrogen, total dissolved phosphorus, seston, BPOM, and chl. $a$ did not show significant relationships with latitude (Table 1).

Taxonomic richness apparently increased with latitude in collector-gatherers/shredders (likelihood ratio test; $\left.\chi^{2}=21.72, P=0.02\right)$, collector-filterers $\left(\chi^{2}=13.85\right.$, $P=0.002)$, and predators $\left(\chi^{2}=34.70, P=0.04\right)$; however, no significant latitudinal pattern was observed in the taxonomic richness of scrapers $\left(\chi^{2}=9.06, P=\right.$ 0.08; Fig. 4).

\section{Bayesian networks}

In the network giving the best representation of the observed data, the relationship between taxonomic richness and latitude was indirect (Fig. 5). Latitude was directly related to disturbance. Disturbance had negative effects on the community densities of collectorgatherers/shredders, collector-filterers, and scrapers, but not on that of predators. The increase in the taxonomic richness of collector-gatherers/shredders and collectorfilterers with latitude was attributed directly to the

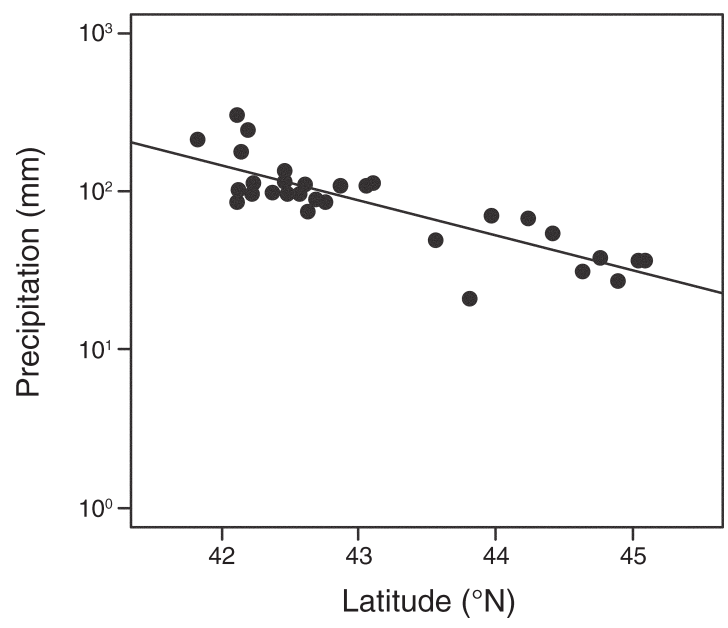

FIG. 3. Regional gradient in accumulated precipitation. 
TABLE 1. Means, standard deviations, and ranges for 12 environmental variables measured in the 30 mountain streams in Hokkaido Island, Japan, and linear regression coefficients and $P$ values for comparisons between latitude and the variables.

\begin{tabular}{|c|c|c|c|c|c|c|}
\hline \multirow[b]{2}{*}{ Environmental variable } & \multirow[b]{2}{*}{ Mean } & \multirow[b]{2}{*}{ SD } & \multicolumn{2}{|c|}{ Range } & \multirow[b]{2}{*}{ Correlation coefficients } & \multirow[b]{2}{*}{$P$} \\
\hline & & & Minimum & Maximum & & \\
\hline Temperature $\left({ }^{\circ} \mathrm{C}\right)$ & 13.4 & 1.2 & 9.3 & 15.0 & 0.11 & 0.56 \\
\hline Precipitation (mm) & 100.4 & 64.4 & 21.0 & 304.0 & -0.70 & $<0.001$ \\
\hline Catchment area $\left(\mathrm{km}^{2}\right)$ & 7.3 & 4.2 & 1.7 & 13.4 & 0.22 & 0.25 \\
\hline Catchment slope (\%) & 17.5 & 5.4 & 8.1 & 26.5 & -0.36 & 0.05 \\
\hline Altitude (m) & 104.5 & 69.9 & 28.0 & 318.0 & -0.01 & 0.96 \\
\hline Froude number & 0.35 & 0.11 & 0.23 & 0.72 & -0.04 & 0.82 \\
\hline Substrate heterogeneity & 0.91 & 0.34 & 0.41 & 1.62 & -0.34 & 0.07 \\
\hline Total dissolved nitrogen $(\mathrm{mg} / \mathrm{L})$ & 0.17 & 0.15 & 0.01 & 0.51 & -0.07 & 0.72 \\
\hline Total dissolved phosphate (mg/L) & 0.021 & 0.013 & 0.007 & 0.055 & 0.14 & 0.45 \\
\hline Seston (mg/L) & 1.49 & 0.82 & 0.29 & 3.49 & 0.33 & 0.08 \\
\hline $\operatorname{BPOM}\left(\mathrm{g} / \mathrm{m}^{2}\right)$ & 1.37 & 0.82 & 0.41 & 3.53 & 0.20 & 0.28 \\
\hline Chlorophyll $a\left(\mathrm{mg} / \mathrm{m}^{2}\right)$ & 8.36 & 6.25 & 0.26 & 25.78 & -0.23 & 0.22 \\
\hline
\end{tabular}

Note: BPOM stands for benthic particulate organic matter.

increase of their respective community densities. The community density of collector-gatherers/shredders $(\mathrm{SPRC}=0.48)$ was more strongly related to their taxonomic richness, compared to the community density of collector-filterers (0.30). The taxonomic richness of collector-filterers was not influenced by other guilds, and that of scrapers was unrelated to latitude-dependent community density. Total dissolved nitrogen and BPOM were positively related to the community density of collector-gatherers/shredders, and seston positively in- fluenced that of collector-filterers, whereas chl. $a$ was not related to scrapers. The process underlying the regional gradient in the predator taxonomic richness appears to be complex. Predator taxonomic richness was positively influenced by their own community density, which was affected by community density of collector-gatherers/ shredders varying with latitude-dependent disturbance. The taxonomic richness of predators was also positively influenced by that of collector-filterers, which was indirectly related to disturbance with latitude. Predator
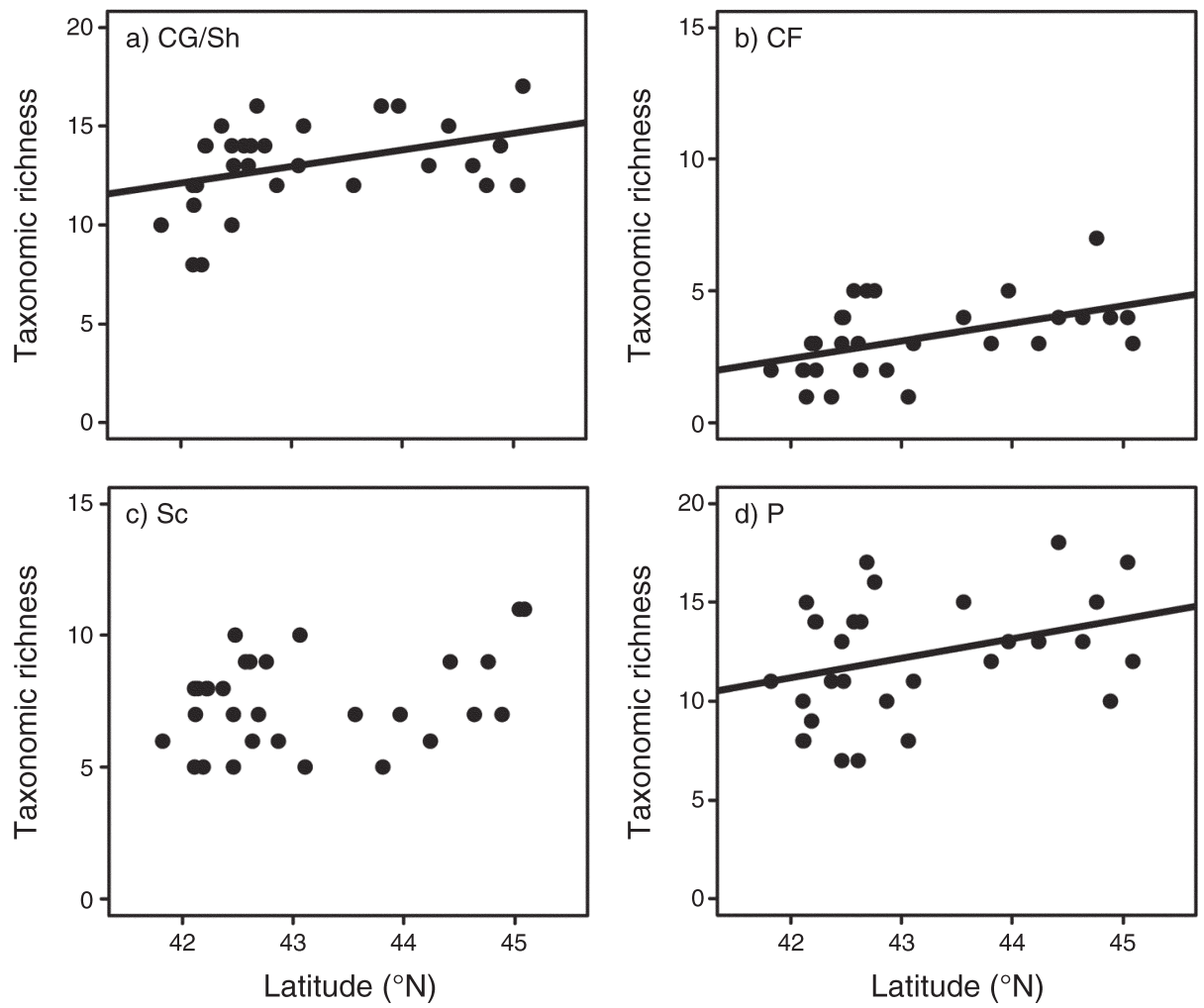

FIG. 4. Regional gradients in the taxonomic richness of (a) collector-gatherers/shredders (CG/Sh), (b) collector-filterers (CF), (c) scrapers $(\mathrm{Sc})$, and $(\mathrm{d})$ predators $(\mathrm{P})$. Solid lines represent significant relationships. 


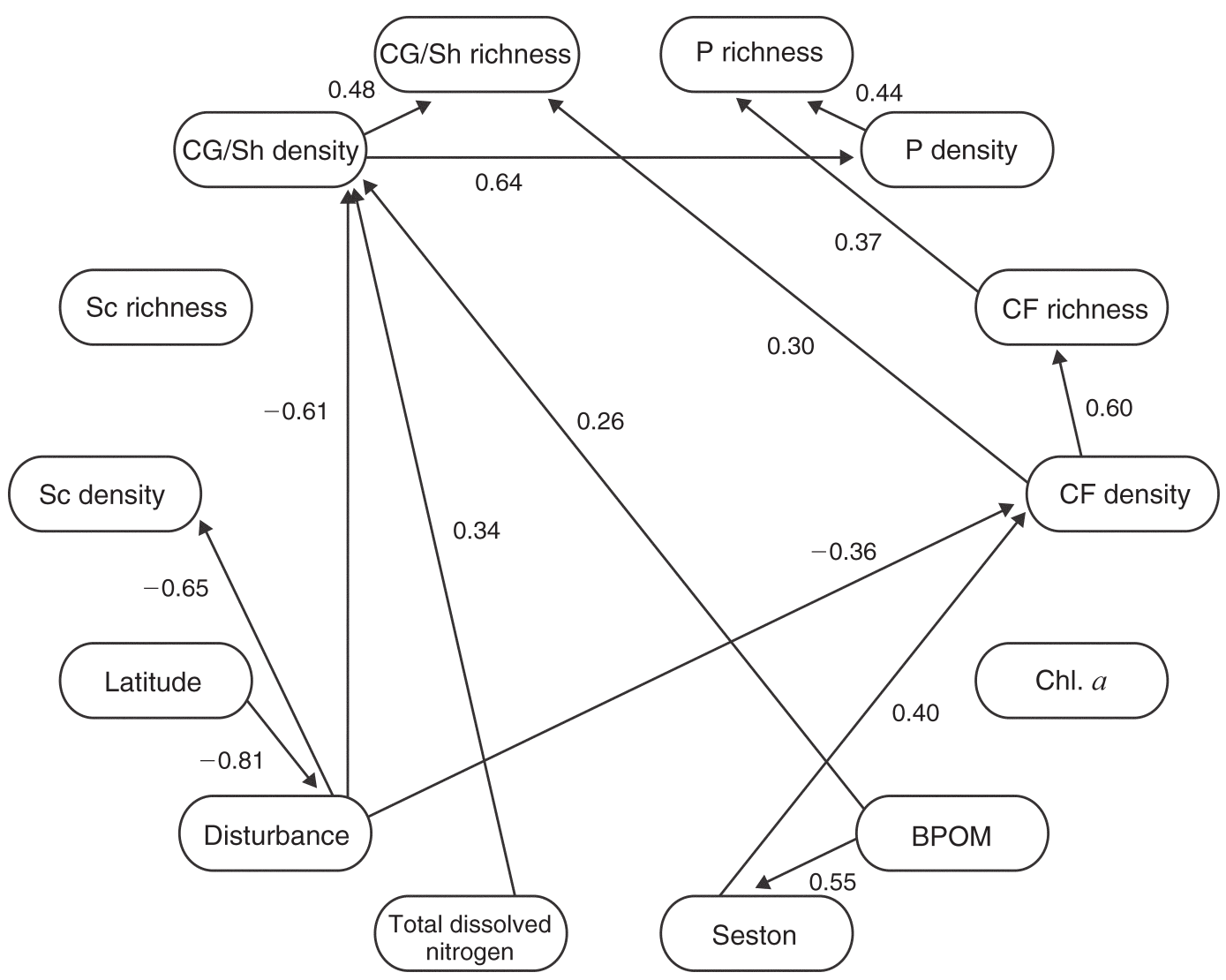

FIG. 5. The network that best represents the data. Rounded rectangles represent variables (i.e., nodes), and arrows represent causal connections between nodes. Numerical values next to arrows show posterior estimates of standardized partial regression coefficients. Abbreviations are: CF, collector-filterers; CG, collector-gatherers; Sc, scrapers; Sh, shredders; P, predators; BPOM, benthic particulate organic matter; Chl. $a$, chlorophyll $a$.

community density $(\mathrm{SPRC}=0.44)$ was more important to their taxonomic richness than the taxonomic richness of collector-filterers (0.37).

\section{DisCUSSION}

Collector-gatherers/shredders, collector-filterers, and predators showed significant regional gradients in taxonomic richness (Fig. 4), but the processes underlying the gradients differed among the guilds (Fig. 5). Variations in the taxonomic richness of the three guilds were explained significantly by their own community densities (Fig. 5). The community densities of collectorgatherers/shredders and collector-filterers were directly influenced by flood disturbance caused by precipitation with latitude (Fig. 3), whereas that of predators was indirectly influenced by the disturbance. Disturbance effects on predators emerged through their prey guilds (collector-gatherers/shredders and collector-filterers). Although the taxonomic richness of collector-gatherers/shredders was also influenced by collector-filterers, disturbance effects were more important for the richness than the other guild effects. These results indicate that flood disturbance was a substantial driver for regional gradients in taxonomic richness and that inter-guild effects were essential for forming the gradient in predator richness.

The taxonomic richness of scrapers did not show a significant pattern with latitude (Fig. 4); it was not influenced by any of the factors related to latitude (Fig. 5). Although the disturbance effects on scraper community density were evidenced by the results of Bayesian network analysis, community density had no effect on the taxonomic richness of scrapers.

\section{Regional gradients in meteorological factors}

Precipitation, which can cause flood disturbances, showed a clear regional latitudinal gradient (Fig. 3). There is a large precipitation gradient across the Japanese archipelago, and Hokkaido Island falls on the northern portion of this gradient, with higher rainfall in the southern part of the island and less in the north (Fig. 1). In contrast, temperature did not show a significant regional gradient (Table 1). Temperature of Hokkaido is affected by latitude, altitude, and sea currents (Saitoh et al. 1998). Warm currents run along the western shores of the island, resulting in a milder temperature in these regions, whereas a cold current prevails along the eastern shores, resulting in a cooler 
temperature in this region. Hence, temperature does not vary simply with latitude (Fig. 1).

\section{Environmental and inter-guild effects on regional gradients}

Regional gradients in taxonomic richness were detected in collector-gatherers/shredders, collector-filterers, and predators (Fig. 4). Although the gradients in the three guilds are the reverse of those most frequently observed for various taxa (Rosenzweig 1995), such inverse patterns have been noted for several taxonomic groups, including stream invertebrate assemblages (Buckley et al. 2003, Boyero et al. 2011). Latitudinal gradients in species richness are generally understood as being generated by both evolutionary and environmental factors (Rosenzweig 1995). However, this study focused on the system assembled from a common species pool; evolutionary factors may thus have little effect on their taxonomic richness (Mori et al. 2010). The observed gradients in the three guilds are considered to be generated by environmental variables and the influence of other guilds (Fig. 5).

The processes underlying the variations in taxonomic richness of collector-filterers and collector-gatherers/ shredders through their own community densities are consistent with the "more individuals" hypothesis (Srivastava and Lawton 1998, Yee and Juliano 2007). This hypothesis postulates that greater productivity supports higher population densities, which lower the extinction rates of rare species, i.e., more individuals give rise to a greater number of species by enhancing the persistence of rare species (Srivastava and Lawton 1998, Mori et al. 2010). Community densities of collectorgatherers/shredders and collector-filterers were positively influenced by their resources (Fig. 5). BPOM and seston, which is derived from BPOM, are food resources for collector-gatherers/shredders and collector-filterers, respectively. Dissolved nitrogen can enhance the growth of microbes that colonize BPOM (Gulis et al. 2004), resulting in high-quality BPOM (e.g., Cross et al. 2006). A high quantity and quality of food resources may have the same function as high productivity (Yee and Juliano 2007), and thus promote an increase in community density, leading to an increase in taxonomic richness. Disturbance can play a similar role to productivity in terms of influencing population densities; flood disturbance depresses the growth of community density, resulting in a decrease in species richness (Mori et al. 2010). Thus, high community density (i.e., more individuals), which was affected by both food resources and disturbance, produced high taxonomic richness in collector-gatherers/shredders and collector-filterers (Fig. $5)$.

The effects of collector-filterer community density on the taxonomic richness of collector-gatherers/shredders can be interpreted in terms of facilitation (i.e., encounters between organisms that benefit at least one of the participants and cause harm to neither [Jones et al.
1997]), although the effects were minor in comparison with collector-gatherer/shredder community density (Fig. 5). Facilitation processes occur when one species makes the local environment more favorable to another or others, either directly (e.g., by reducing thermal stress or providing refugia) or indirectly (e.g., by removing competitors or increasing food resources). In stream ecosystems, net-spinning caddisflies (e.g., Hydropsychidae), which belong to the collector-filterer guild, construct fixed nets to capture drifting food particles (Merritt and Cummins 1996), and these nets result in an increase in habitat complexity (Englund and Evander 1999). A higher community density of collector-filterers may, therefore, lead to an increase in the taxonomic richness of collector-gatherers/shredders through the amelioration of habitat complexity.

Variations in predator taxonomic richness were determined through two processes attributed to predator-prey relationships (Fig. 5). The first process, which worked from collector-gatherers/shredders to predators, can be interpreted by the more individuals hypothesis (Srivastava and Lawton 1998, Yee and Juliano 2007), as it is for collector-gatherers/shredders and collectorfilterers. Collector-gatherers/shredders are food resources for predators, and the total biomass of collectorgatherers/shredders increased with their community density. Hence, a bottom-up process from community density (i.e., higher biomass) in collector-gatherers/ shredders to taxonomic richness in predators through their own community density was observed (Fig. 5).The second process, which worked from collector-filterers to predators, may be understood in terms of food-niche dimensions (Jeffries and Lawton 1985, Warren and Gaston 1992). Prey species types, i.e., groups of prey with similar ecological features, such as body size and habitat use, can be one of the niche dimensions for predator species. Hence, higher prey species richness (i.e., more niche dimensions) result in higher predator species richness (Fig. 5; Arnold 1972, Jeffries and Lawton 1985).

An alternative explanation for the regional gradients found in collector-gatherers/shredders, collector-filterers, and predators is that common variables other than disturbance individually influence the taxonomic richness of these three guilds, without the involvement of inter-guild effects (Warren and Gaston 1992). Latitude did not directly affect the three guilds in this study (Fig. 5), and thus, the regional gradients in the three guilds may not be influenced by unknown common variables that vary with latitude.

In this study we demonstrated that the regional gradients in taxonomic richness of collector-gatherers/ shredders, collector-filterers, and predators originated indirectly from a latitudinal variation in disturbance (Fig. 5). Disturbance effects on the latitudinal gradients in species richness of stream invertebrate assemblages have been reported (e.g., Vinson and Hawkins 2003, Brown and Swan 2010). Its underlying mechanism has 
been considered in terms of environmental filtering, whereby the survival or elimination of species in assemblages is filtered by environmental conditions (Weiher and Keddy 1999, Bêche and Statzner 2009). However, this study revealed that both disturbance and bottom-up inter-guild effects were essential to forming the regional spatial pattern in predator taxonomic richness. Although effects of biotic interactions on species richness have been considered less important in stream invertebrates (Vinson and Hawkins 1998), significant relationships between predator and prey assemblages have been suggested (Jeffries and Lawton 1985, Warren and Gaston 1992, Dudgeon et al. 2010), and predator-prey effects (i.e., inter-guild effects) on predator richness were found in this study. Inter-guild effects may be hindered by greater abiotic and biotic heterogeneity at global and continental scales (Freestone et al. 2011), and then detection of inter-guild effects may depend on spatial scale. Hence, by downscaling to a regional scale where stream invertebrates have been assembled from a common species pool, such as on Hokkaido Island (Mori et al. 2010), we may have detected the bottom-up inter-guild effects on the regional gradient in predator taxonomic richness, and the recognition that stream invertebrate assemblages are less constrained by biotic interactions should be reconsidered based on spatial scales.

Vinson and Hawkins (1998, 2003) comprehensively reviewed empirical studies on latitudinal patterns in the species diversity of stream invertebrate assemblages and showed that latitudinal patterns depended on the types of assemblage. Thus, analyses that include several different types of assemblage may prove problematic, in that different spatial patterns could become mingled, thereby hindering determination of the correspondence between assemblage structure and causal factors. The current approach focusing on the regional patterns succeeded in revealing the underlying processes of the regional gradients. The present findings at a regional scale, however, cannot simply be extended to latitudinal gradients at continental and global scales, because there are significant spatial heterogeneities in both biotic and abiotic factors at large spatial scales (Underwood et al. 2005). A large collection of empirical studies that take inter-guild effects into consideration at regional scales is therefore needed to resolve these problems and to elucidate the true latitudinal gradients and/or other patterns in species diversity. Further examinations of inter-guild relationships would help to bridge the gap between empirical and theoretical studies on the determinants of latitudinal gradients.

\section{ACKNOWLEDGMENTS}

We thank M. Murakami, T. Noda, N. Kuhara, and G. Takimoto for insightful discussions and comments; M. Miura for his help with the fieldwork; and $\mathrm{H}$. Asano and $\mathrm{K}$. Ono for the identification of stream invertebrates. We are also grateful to the staff and students at the Tomakomai Experimental Forest, Hokkaido University, for logistic support during the study. This study was supported by a Grant-in-Aid for JSPS Fellows (07J05487).

\section{Literature Cited}

Allen, A. P., J. H. Brown, and J. F. Gillooly. 2002. Global biodiversity, biochemical kinetics, and the energetic-equivalence rule. Science 297:1545-1548.

Arnold, S. J. 1972. Species densities of predators and their prey. American Naturalist 106:220-236.

Bêche, L. A., and B. Statzner. 2009. Richness gradients of stream invertebrates across the USA: taxonomy- and traitbased approaches. Biodiversity and Conservation 18:39093930.

Bøttcher, S. G., and C. Dethlefsen. 2003. Deal: a package for learning Bayesian networks. Journal of Statistical Software 8: $1-40$.

Boyero, L., et al. 2011. Global distribution of a key trophic guild contrasts with common latitudinal diversity patterns. Ecology 92:1839-1848.

Brown, B. L., and C. M. Swan. 2010. Dendritic network structure constrains metacommunity properties in riverine ecosystems. Journal of Animal Ecology 79:571-580.

Buckley, H. L., T. E. Miller, A. M. Ellison, and N. J. Gotelli. 2003. Reverse latitudinal trends in species richness of pitcherplant food webs. Ecology Letters 6:825-829.

Cross, W. F., J. B. Wallace, A. D. Rosemond, and S. L. Eggert. 2006. Whole-system nutrient enrichment increases secondary production in a detritus-based ecosystem. Ecology 87:15561565.

Dudgeon, D., F. K. W. Cheung, and S. K. Mantel. 2010. Foodweb structure in small streams: do we need different models for the tropics? Journal of the North American Benthological Society 29:395-412.

Englund, G. 1993. Interactions in a lake outlet stream community: direct and indirect effects of net-spinning caddis larvae. Oikos 66:431-438.

Englund, G., and D. Evander. 1999. Interactions between sculpins, net-spinning caddis larvae and midge larvae. Oikos 85:117-126.

Freestone, A. L., R. W. Osman, G. M. Ruiz, and M. E. Torchin. 2011. Stronger predation in the tropics shapes species richness patterns in marine communities. Ecology 92: 983-993.

Fuhrman, J. A., J. A. Steele, I. Hewson, M. S. Schwalbach, M. V. Brown, J. L. Green, and J. H. Brown. 2008. A latitudinal diversity gradient in planktonic marine bacteria. Proceedings of the National Academy of Sciences USA 105: $7774-7778$

Gulis, V., A. D. Rosemond, K. Suberkropp, H. S. Weyers, and J. P. Benstead. 2004. Effects of nutrient enrichment on the decomposition of wood and associated microbial activity in streams. Freshwater Biology 49:1437-1447.

Hawkins, B. A., E. E. Porter, and J. A. F. Diniz. 2003 Productivity and history as predictors of the latitudinal diversity gradient of terrestrial birds. Ecology 84:1608-1623.

Hawkins, R. D., G. C. Hon, and B. Ren. 2010. Next-generation genomics: an integrative approach. Nature Reviews Genetics 11:476-486.

Hillebrand, H. 2004. On the generality of the latitudinal diversity gradient. American Naturalist 163:192-211.

Hixon, M. A., and J. P. Beets. 1993. Predation, prey refuges, and the structure of coral-reef fish assemblages. Ecological Monographs 63:77-101.

Hubbell, S. P. 2001. The unified neutral theory of biodiversity and biogeography. Princeton University Press, Princeton, New Jersey, USA.

Huston, M. A. 1999. Local processes and regional patterns: appropriate scales for understanding variation in the diversity of plants and animals. Oikos 86:393-401.

Japan Meteorological Agency. 2002. Mesh climate data of Japan. Japan Meteorological Agency, Tokyo, Japan. 
Jeffries, M. J., and J. H. Lawton. 1985. Predator-prey ratios in communities of freshwater invertebrates: the role of enemy free space. Freshwater Biology 15:105-112.

Jones, C. G., J. H. Lawton, and M. Shachak. 1997. Positive and negative effects of organisms as physical ecosystem engineers. Ecology 78:1946-1957.

Kawai, T., and K. Tanida. 2005. Aquatic insects of Japan: manual with keys and illustrations. Tokai University Press, Tokyo, Japan.

Lyons, S. K., and M. R. Willig. 1999. A hemispheric assessment of scale dependence in latitudinal gradients of species richness. Ecology 80:2483-2491.

McMahon, S. M. 2005. Quantifying the community: using Bayesian learning networks to find structure and conduct inference in invasions biology. Biological Invasions 7:833844.

Merritt, R. W., and K. W. Cummins. 1996. An introduction to the aquatic insects of North America. Third edition. Kendall Hunt Publishing, Dubuque, Iowa, USA.

Mori, T., M. Murakami, and T. Saitoh. 2010. Latitudinal gradients in stream invertebrate assemblages at a regional scale on Hokkaido Island, Japan. Freshwater Biology 55: $1520-1532$.

Needham, C. J., J. R. Bradford, A. J. Bulpitt, and D. R. Westhead. 2006. Inference in Bayesian networks. Nature Biotechnology 24:51-53.

Pearson, R. G., and L. Boyero. 2009. Gradients in regional diversity of freshwater taxa. Journal of the North American Benthological Society 28:504-514.

Poff, N. L., J. D. Olden, N. K. M. Vieira, D. S. Finn, M. P. Simmons, and B. C. Kondratieff. 2006. Functional trait niches of North American lotic insects: traits-based ecological applications in light of phylogenetic relationships. Journal of the North American Benthological Society 25: 730-755.

R Development Core Team. 2009. R: a language and environment for statistical computing. R Foundation for Statistical Computing, Vienna, Austria.

Rohde, K. 1992. Latitudinal gradients in species-diversity: the search for the primary cause. Oikos 65:514-527.

Rosenzweig, M. L. 1995. Species diversity in space and time. Cambridge University Press, Cambridge, UK.

Saitoh, T., N. C. Stenseth, and O. N. Bjornstad. 1998. The population dynamics of the vole Clethrionomys rufocanus in
Hokkaido, Japan. Researches on Population Ecology 40:6176.

Scheiner, S. M., and M. R. Willig. 2005. Developing unified theories in ecology as exemplified with diversity gradients. American Naturalist 166:458-469.

Scutari, M. 2010. Learning Bayesian networks with the bnlearn R package. Journal of Statistical Software 35:1-22.

Sokal, R. R., and F. J. Rohlf. 1995. Biometry. Third edition. Freeman, New York, New York, USA.

Srivastava, D. S., and J. H. Lawton. 1998. Why more productive sites have more species: An experimental test of theory using tree-hole communities. American Naturalist 152:510-529.

Underwood, N., P. Hamback, and B. D. Inouye. 2005. Largescale questions and small-scale data: empirical and theoretical methods for scaling up in ecology. Oecologia 145:177178.

van Steensel, B., U. Braunschweig, G. J. Filion, M. Chen, J. G. van Bemmel, and T. Ideker. 2010. Bayesian network analysis of targeting interactions in chromatin. Genome Research 20: 190-200.

Vinson, M. R., and C. P. Hawkins. 1998. Biodiversity of stream insects: variation at local, basin, and regional scales. Annual Review of Entomology 43:271-293.

Vinson, M. R., and C. P. Hawkins. 2003. Broad-scale geographical patterns in local stream insect genera richness. Ecography 26:751-767.

Wallace, J. B., S. L. Eggert, J. L. Meyer, and J. R. Webster. 1999. Effects of resource limitation on a detrital-based ecosystem. Ecological Monographs 69:409-442.

Warren, P. H., and K. J. Gaston. 1992. Predator-prey ratios: a special case of a general pattern. Philosophical Transactions of the Royal Society B 338:113-130.

Weiher, E., and P. A. Keddy. 1999. Ecological assembly rules: perspectives, advances, retreats. Cambridge University Press, Cambridge, UK.

Willig, M. R., D. M. Kaufman, and R. D. Stevens. 2003. Latitudinal gradients of biodiversity: pattern, process, scale, and synthesis. Annual Review of Ecology, Evolution, and Systematics 34:273-309.

Yee, D. A., and S. A. Juliano. 2007. Abundance matters: a field experiment testing the more individuals hypothesis for richness-productivity relationships. Oecologia 153:153-162.

\title{
Supplemental Material
}

Appendix A

Characteristics of the study streams on Hokkaido Island, Japan (Ecological Archives E095-012-A1).

\begin{abstract}
Appendix B
Description of sampling methods (Ecological Archives E095-012-A2).
\end{abstract}

Appendix C

Description of construction of Bayesian networks in the present study (Ecological Archives E095-012-A3). 